\title{
Clopidogrel Response Variability in Unruptured Intracranial Aneurysm Patients Treated with Stent-Assisted Endovascular Coil Embolization : Is Follow-Up Clopidogrel Response Test Necessary?
}

Min Soo Kim, M.D., Eun Suk Park, M.D., Ph.D., Jun Bum Park, M.D., Ph.D., In Uk Lyo, M.D., Ph.D., Hong Bo Sim, M.D., Ph.D., Soon Chan Kwon, M.D., Ph.D.

Department of Neurosurgery, Ulsan University Hospital, University of Ulsan College of Medicine, Ulsan, Korea

Objective : The purpose of this study was to analyze the variability of clopidogrel responses according to duration of a clopidogrel drug regimen after stent-assisted coil embolization $(S A C)$, and to determine the correlation between the variability of clopidogrel responses and thromboembolic or hemorrhagic complications.

Methods : A total of 47 patients who underwent SAC procedures to treat unruptured intracranial aneurysms were enrolled in the study. Preoperatively, patients received more than seven days of aspirin (100 mg) and clopidogrel (75 mg), daily. P2Y12 reaction unit (PRU) was checked with the VerifyNow test one day before the procedure (pre-PRU) and one month after the procedure (post-PRU). PRU variability was calculated as the difference between the initial response and the follow-up response. Patients were sorted into two groups based on their response to treatment : responsive and hypo-responsive.

Results : PRU variability was significantly greater in the hypo-responsive group when compared to the responsive group ( $p=0.019$ ). Pre-PRU and serum platelets counts were significantly correlated with PRU variation ( $p=0.005$ and $p=0.004$, respectively). Although thromboembolic complication had no significant correlated factors, hemorrhagic complication was correlated with pre-PRU $(p=0.033)$.

Conclusion : In conclusion, variability of clopidogrel responses during clopidogrel medication was correlated to serum platelet counts and the initial clopidogrel response. Thromboembolic and hemorrhagic complications did not show correlation with the variability of clopidogrel response, or the clopidogrel response after one month of medication; however, hemorrhagic complication was associated with initial clopidogrel response. Therefore, it is recommended to test patients for an initial clopidogrel response only, as further tests would be insignificant.

Key Words : Intracranial aneurysm · Stents · Thromboembolism · Platelet aggregation inhibitors.

- Received : March 31, 2017 •Revised : May 31, 2017 • Accepted : June 29, 2017

- Address for reprints : Soon Chan Kwon, M.D., Ph.D.

Department of Neurosurgery, Ulsan University Hospital, University of Ulsan College of Medicine, 877 Bangeojinsunhwando-ro, Dong-gu, Ulsan 44033, Korea Tel : +82-52-250-7139, Fax : +82-52-250-7138, E-mail : nskwon.sc@gmail.com 


\section{INTRODUCTION}

Endovascular coil embolization for the treatment of unruptured intracranial aneurysms (UIA) is relatively safe and effective compared with other surgical treatments such as aneurysm clipping, which has been increasingly performed since its introduction into clinical practice ${ }^{3,23)}$. Particularly, stent-assisted coil embolization (SAC) procedures, which result in increased packing density and decreased rates of coil migration into the parent artery, have gained widespread use as an effective treatment for UIA, and are particularly useful for wide-necked aneurysms ${ }^{9,22,29)}$. Despite advances in technique and management in recent years, this procedure is associated with thromboembolic complications ${ }^{12)}$.

Dual antiplatelet premedication protocol of $100 \mathrm{mg}$ of aspirin and $75 \mathrm{mg}$ of clopidogrel daily for at least seven days prior to SAC has been widely used for decreasing thromboembolic risk $^{13,20)}$. Despite the routine use of dual antiplatelet premedication, thromboembolic complications continue to be encountered ${ }^{177}$. Recent studies have resulted in a growing body of neuro-intervention literature indicating that individual variability in patient response to antiplatelet therapy, especially to clopidogrel, may be associated with some of the thromboembolic complications encountered after endovascular procedures ${ }^{1)}$. Several studies have reported a $7 \%$ to $40 \%$ incidence of thromboembolic events after SAC, in patients with high on-treatment platelet reactivity $(\mathrm{HTPR})^{11)}$.

In cardiology, many publications suggest that the variability of platelet response in patients treated with clopidogrel is correlated with the cytochrome P450 genotype, diabetes, and chronic kidney disease ${ }^{2,15,28)}$. However, in the neuro-intervention literature, there is no established link between the variability of clopidogrel response and cerebral infarction.

Therefore, the purpose of our study was to analyze the variability of clopidogrel responses according to the duration of post-SAC clopidogrel regimens, and to assess any possible correlation between the variability of clopidogrel responses and thromboembolic or hemorrhagic complications.

\section{MATERIALS AND METHODS}

\section{Study design}

This retrospective study included patients from a prospec- tively collected database between January 2014 and June 2015. Total of 202 patients with UIA were treated in a single center. Inclusion criteria were as follows : patients underwent a SAC procedure due to UIA with dome to neck ratio $>2$, had a risk of coil prolapse, had a need for flow diversion, and had out-patient department follow-up data for more than one year after the procedure. In addition, patients who had measured antiplatelet response assays one day before the procedure and one month after the procedure were included. Exclusion criteria were as follows : patients who were treated with additional coil packing with stent assistance at a previous procedure site, treated with a flow diverter, such as Pipeline (EV3, Irvine, CA, USA), or failed of stent deployment. After inclusions and exclusions, 47 patients were enrolled into this study. This study was approved by our institutional review board.

\section{Patient data}

Patient clinical data, laboratory data, and preoperative druguse history were obtained by a retrospective chart review. Clinical data consisted of age, sex, diabetes mellitus (DM) status, blood pressure, history of smoking, alcohol use, history of stroke, history of heart disease, and body mass index (BMI). Laboratory data consisted of glomerular filtration rate, platelet count, cholesterol levels, triglyceride levels, high-density lipoprotein levels, and low-density lipoprotein levels ${ }^{7,15,18,21)}$. These factors were defined as follows : DM and hypertension (HTN) were defined by medical treatment after diagnosis, patients were considered smokers only if they currently smoked, alcoholism was defined as the consumption of more than 14 standard drinks per week or four drinks per day, history of stroke was determined by a previous cerebral infarction or intracranial hemorrhage, and history of heart disease included myocardial infarction, angina, valve disease, congenital heart disease, or previous heart operations. BMI was checked at admission and laboratory data were checked in the evening of the admission day, one day before the procedure. In addition, because clopidogrel is well known to be metabolized by the cytochrome P450 enzyme in the liver, we also checked whether patients were using other drugs that may compete with clopidogrel during metabolism, which includes statins, metformin, proton pump inhibitors (PPI), histamine-2 receptor antagonists, selective serotonin reuptake inhibitors (SSRI), calcium channel blockers (CCB), $\beta$-blocker, angiotensin-converting enzyme inhibitors (ACE inhibitor), angiotensin II receptor 
blockers (ARB), diuretics, and warfarin ${ }^{19,27,30)}$.

\section{Premedication protocol and antiplatelet response assay}

Our protocol of antiplatelet premedication called for at least seven days of dual antiplatelet medication with daily doses of 100 $\mathrm{mg}$ of aspirin and $75 \mathrm{mg}$ of clopidogrel. On the day prior to the coiling procedure, we checked the pre-procedural VerifyNow P2Y12 Assays (Accumetrics, San Diego, CA, USA), which determined pre-procedural P2Y12 reaction unit (pre-PRU) for clopidogrel $^{24)}$. An abnormal antiplatelet response was defined as $\geq 240$ $\mathrm{PRUs}^{5}$. After the procedure, the antiplatelet regimen remained the same as before the procedure, regardless of the antiplatelet response assay value. In addition, the follow-up antiplatelet response assay (post-PRU) was assessed 30 days after the procedure, with the same protocol as above. In general, three months of dual antiplatelet therapy is given and then changed to monotherapy, but for some patients the duration of clopidogrel use may change depending on the symptoms. PRU variability was defined as the decreased value from pre-PRU and post-PRU.

\section{Procedure}

Endovascular treatment was performed under general anesthesia, by using a biplane angiographic unit (Artis zee, Siemens, Erlangen, Germany). All patients in this study were treated with SAC. The choice of stent was determined by vessel structure or the clinician's individual policy. During the procedure, systemic anticoagulatives with heparin were administered from the beginning of the procedure. Heparin was given as a continuous infusion throughout the procedure to maintain an activated clotting time that was 2-3 times longer than the baseline clotting time. To evaluate the thromboembolic risk associated with the procedure, the size and location of the aneurysm was measured by an angiography before the procedure, and the degree of occlusion and thrombus formation in the stent were also immediately measured by the post-procedural angiography. Aneurysm occlusion status was determined by the Raymond Roy occlusion classification ${ }^{25}$.

\section{Follow-up}

Follow-up brain magnetic resonance imaging (MRI) scans were performed twice : one day, and one year after the procedure. Thromboembolic infarction was defined as a symptomatic ischemic event, such as transient ischemic attack, or as- ymptomatic ischemic event with evidence of infarction on diffusion-weighted imaging occurring after discharge. In addition, we analyzed the vascular territory of the ischemic attack according to vessel location of the inserted stent. Hemorrhagic complications were classified as major or minor according to the Thrombolysis in Myocardial Infarction (TIMI) bleeding criteria ${ }^{16)}$. All MRIs and angiographies were reviewed by two independent, board-certified radiologists. If disagreement occurred, a decision was made by consensus after additional review of the MRIs and angiographies.

\section{Statistics}

Statistical analyses were performed using SPSS version 21.0 (IBM Corp., Armonk, NY, USA). Baseline characteristics of clopidogrel response were assessed and compared between the two groups (responsive vs. hypo-responsive) using the chisquare test or Fisher's exact test in categorical variables, and Student's t-test or Mann-Whitney test were used for parametric variables. To assess the degree of PRU variation and thromboembolic infarction or hemorrhagic complication, univariate analysis of clinical, radiological, laboratory findings, and druguse history was performed using a chi-square test or Fisher's exact test, and a Student's t-test or Mann-Whitney test. Variables with a $p$ value of $<0.10$ in univariate analysis were then chosen for multivariate analysis using a logistic regression model. In all analyses, $p$ values $\leq 0.05$ were defined as statistically significant.

\section{RESULTS}

\section{Responsive group vs. hypo-responsive group}

Among the 47 patients who had undergone SAC, 10 patients (21.3\%) were included in the hypo-responsive group, and 37 (78.7\%) were in the responsive group. Mean values of pre-PRU were $271.10 \pm 26.52$ in the hypo-responsive group, and 181.27 \pm 44.4 in responsive group $(p<0.001)$. Overall mean value of PRU variability was $128.55 \pm 9.55(171.00 \pm 59.30$ in the hypo-responsive group vs. $117.08 \pm 62.94$ in the responsive group). In the hypo-responsive group, PRU was significantly more variable than in the responsive group $(p=0.019)$. No factor was significantly different between the two groups except the pre-PRU and PRU variability (Table 1). 
Table 1. Baseline characteristics between hypo-responsive group and responsive group according to initial clopidogrel response

\begin{tabular}{|c|c|c|c|}
\hline & Hypo-responsive group (PRU $\geq 240, n=10$ ) & Responsive group (PRU $<240, n=37$ ) & $p$-value* \\
\hline \multicolumn{4}{|l|}{ Clinical } \\
\hline Age (years) & $59.10 \pm 10.71$ & $55.27 \pm 11.49$ & 0.348 \\
\hline Gender (female) & $9(90)$ & $22(59.5)$ & 0.131 \\
\hline Diabetes & $2(20)$ & $4(10.8)$ & 0.594 \\
\hline Hypertension & $4(40)$ & $14(37.8)$ & 1.000 \\
\hline Smoking & $2(20)$ & $4(10.8)$ & 0.594 \\
\hline Alcoholism & 0 & 0 & - \\
\hline History of stroke & $1(10)$ & $4(10.8)$ & 1.000 \\
\hline Heart problem & 0 & $2(5.4)$ & 1.000 \\
\hline $\operatorname{BMI}\left(\mathrm{kg} / \mathrm{m}^{2}\right)$ & $25.86 \pm 2.85$ & $24.56 \pm 3.52$ & 0.290 \\
\hline \multicolumn{4}{|l|}{ Laboratory } \\
\hline Pre-PRU & $271.10 \pm 26.52$ & $181.27 \pm 44.4$ & $<0.001$ \\
\hline Post-PRU & $100.10 \pm 79.29$ & $64.19 \pm 48.85$ & 0.227 \\
\hline PRU variability & $171.00 \pm 59.30$ & $117.08 \pm 62.94$ & 0.019 \\
\hline Cholesterol (mg/dL) & $151.75 \pm 25.20$ & $184.21 \pm 75.18$ & 0.222 \\
\hline $\mathrm{TG}(\mathrm{mg} / \mathrm{dL})$ & $92.75 \pm 44.33$ & $157.24 \pm 170.06$ & 0.155 \\
\hline $\mathrm{HDL}(\mathrm{mg} / \mathrm{dL})$ & $53.75 \pm 12.97$ & $47.88 \pm 16.66$ & 0.165 \\
\hline $\mathrm{LDL}(\mathrm{mg} / \mathrm{dL})$ & $94.88 \pm 21.93$ & $103.67 \pm 31.31$ & 0.459 \\
\hline $\mathrm{GFR}(\mathrm{mL} / \mathrm{min})$ & $88.40 \pm 18.48$ & $92.58 \pm 15.35$ & 0.468 \\
\hline Platelets $\left(10^{3} / \mu \mathrm{L}\right)$ & $232.90 \pm 54.16$ & $230.16 \pm 57.12$ & 0.893 \\
\hline \multicolumn{4}{|l|}{ Medications } \\
\hline Statin & $5(50)$ & $13(35.1)$ & 0.473 \\
\hline Metformin & $2(20)$ & $2(5.4)$ & 0.194 \\
\hline PPI & 0 & $3(8.1)$ & 1.000 \\
\hline H2-blocker & $4(40)$ & $19(51.4)$ & 0.724 \\
\hline SSRIS & $1(10)$ & $1(2.7)$ & 0.384 \\
\hline$\beta$-blocker & 0 & $3(8.1)$ & 1.000 \\
\hline $\mathrm{CCB}$ & $3(30)$ & $11(29.7)$ & 1.000 \\
\hline ACEi or ARB & $3(30)$ & $10(27)$ & 1.000 \\
\hline Diuretics & $1(10)$ & $3(6.1)$ & 1.000 \\
\hline Nitrate & 0 & 0 & - \\
\hline Warfarin & $1(10)$ & $1(2.7)$ & 0.384 \\
\hline
\end{tabular}

Values are presented as mean \pm standard deviation or number (\%). ${ }^{*}$-value was determined with the chi-square test or Fisher's exact test in categorical variables and Student's t-test or Mann-Whitney test in parametric variables. PRU : P2Y12 receptor reaction unit, BMI : body mass index, pre-PRU : P2Y12 receptor reaction unit at admission, post-PRU : P2Y12 receptor reaction unit at 1 month after the procedure, PRU variability : pre-PRUpost-PRU, TG : triglyceride, HDL : high density lipoprotein, LDL : low density lipoprotein, GFR : glomerular filtration rate, PPI : proton pump inhibitor, H2blocker : histamine-2 receptor antagonist, SSRI : selective serotonin reuptake inhibitor, CCB : calcium channel blocker, ACEi : angiotensin-converting enzyme inhibitor, ARB : angiotensin II receptor blocker

\section{PRU variability}

According to mean value of PRU variability, patients were divided into a "large variation" group (PRU $\geq 128.55, \mathrm{n}=27[57.4 \%])$ and a "small variation" group (PRU<128.55, $\mathrm{n}=20$ [42.6\%]). In univariate analysis, comparison of the two groups showed that HTN and ACE inhibitor or ARB usage was significantly more frequent in the Large variation group $(p=0.026$ and $p=0.004$, respectively). In addition, pre-PRU and serum platelets count 
were significantly higher in Large variation group $(p=0.008$, and $p=0.001$, respectively). In multivariate analysis, only prePRU and serum platelets were significant correlated with PRU variation count $(p=0.005$, odds ratio [OR] 1.034, 95\% confi- dence interval $[\mathrm{CI}] 1.010-1.059 ; p=0.004$, OR 1.043, 95\% CI 1.013-1.073, respectively). No other variables showed a statistically significant correlation (Table 2).

Table 2. Clinical, laboratory, and medication variables associated with PRU variability divided with mean value of PRU variability (128.55) on univariate analysis and multivariate logistic analysis

\begin{tabular}{|c|c|c|c|c|}
\hline & $\begin{array}{c}\text { Large variation } \\
\text { (variation } \geq 128.55, \mathrm{n}=27 \text { ) }\end{array}$ & $\begin{array}{c}\text { Small variation } \\
(\text { variation }<128.55, \mathrm{n}=20)\end{array}$ & $\begin{array}{l}\text { Univariate } \\
(p \text {-value* })\end{array}$ & $\begin{array}{c}\text { Multivariate } \\
\text { (p-value }[\mathrm{OR}, 95 \% \mathrm{CI}])\end{array}$ \\
\hline \multicolumn{5}{|l|}{ Clinical } \\
\hline Age (years) & $55.70 \pm 9.47$ & $56.60 \pm 3.68$ & 0.792 & \\
\hline Gender (female) & $20(74.7)$ & $11(55)$ & 0.172 & \\
\hline Diabetes & $4(14.8)$ & $2(10)$ & 1.000 & \\
\hline Hypertension & $14(51.9)$ & $4(20)$ & 0.026 & $0.353(4.579,0.185-113.284$ \\
\hline Smoking & $4(14.8)$ & $2(10)$ & 1.000 & \\
\hline Alcohol & 0 & 0 & - & \\
\hline History of stroke & $3(11.1)$ & $2(10)$ & 1.000 & \\
\hline Heart problem & $1(3.7)$ & $1(5)$ & 1.000 & \\
\hline BMI $\left(\mathrm{kg} / \mathrm{m}^{2}\right)$ & $25.01 \pm 3.63$ & $24.60 \pm 3.13$ & 0.689 & \\
\hline \multicolumn{5}{|l|}{ Laboratory } \\
\hline Pre-PRU & $220.11 \pm 35.82$ & $173.75 \pm 66.01$ & 0.008 & $0.005(1.034,1.010-1.059)$ \\
\hline PRU hypo-responder (pre-PRU $\geq 240$ ) & $8(25.6)$ & $2(10)$ & 0.154 & \\
\hline Cholesterol (mg/dL) & $192.39 \pm 85.37$ & $162.00 \pm 34.44$ & 0.193 & \\
\hline $\mathrm{TG}(\mathrm{mg} / \mathrm{dL})$ & $160.04 \pm 200.07$ & $125.00 \pm 65.49$ & 0.703 & \\
\hline $\mathrm{HDL}(\mathrm{mg} / \mathrm{dL})$ & $51.65 \pm 18.47$ & $45.67 \pm 11.91$ & 0.357 & \\
\hline LDL (mg/dL) & $106.09 \pm 23.18$ & $96.67 \pm 36.40$ & 0.347 & \\
\hline GFR (mL/min) & $91.95 \pm 17.81$ & $91.33 \pm 13.44$ & 0.897 & \\
\hline Platelets $\left(10^{3} / \mu \mathrm{L}\right)$ & $253.81 \pm 48.92$ & $199.60 \pm 50.21$ & 0.001 & $0.004(1.043,1.013-1.073)$ \\
\hline \multicolumn{5}{|l|}{ Medications } \\
\hline Statin & $11(40.7)$ & $7(35)$ & 0.689 & \\
\hline Metformin & $4(14.8)$ & 0 & 0.126 & \\
\hline PPI & $2(7.4)$ & $1(5)$ & 1.000 & \\
\hline H2-blocker & $14(51.9)$ & $9(45)$ & 0.642 & \\
\hline SSRIS & $2(7.4)$ & 0 & 0.500 & \\
\hline$\beta$-blocker & $2(7.4)$ & $1(5)$ & 1.000 & \\
\hline$C C B$ & $10(37)$ & $4(20)$ & 0.207 & \\
\hline ACEi or ARB & $11(40.7)$ & $2(10)$ & 0.020 & $0.699(0.487,0.013-18.781)$ \\
\hline Diuretics & $4(8.5)$ & 0 & 0.126 & \\
\hline Nitrate & 0 & 0 & - & \\
\hline Warfarin & $1(3.7)$ & $1(5)$ & 1.000 & \\
\hline
\end{tabular}

Values are presented as mean \pm standard deviation or number (\%) unless otherwise indicated. ${ }^{*} p$-value was determined with the chi-square test or Fisher's exact test in categorical variables and Student's t-test or Mann-Whitney test in parametric variables. PRU : P2Y12 receptor reaction unit, OR : odds ratio, $\mathrm{Cl}$ : confidence interval, BMI : body mass index, pre-PRU : P2Y12 receptor reaction unit at admission, TG : triglyceride, HDL : high density lipoprotein, LDL : low density lipoprotein, GFR : glomerular filtration rate, PPI : proton pump inhibitor, H2-blocker : histamine-2 receptor antagonist, SSRI : selective serotonin reuptake inhibitor, CCB : calcium channel blocker, ACEi : angiotensin-converting enzyme inhibitor, ARB : angiotensin II receptor blocker 


\section{Thromboembolic infarction, hemorrhagic complication}

Among radiologic factors, the mean size of aneurysms was $4.2 \pm 0.32 \mathrm{~mm}$. Twenty-six (55.3\%) aneurysms were located on the internal carotid artery, 11 (23.4\%) on the anterior cerebral artery, seven (14.9\%) aneurysms on the middle cerebral artery, and three $(6.4 \%)$ aneurysms on the posterior circulation. No thrombi accumulated in the stent during the procedure. Total occlusion occurred in 38 cases (80.9\%), residual neck of the aneurysm was evident in four cases (8.5\%), and incomplete occlusion occurred in five cases $(10.6 \%)$. Thirty-five patients $(74.5 \%)$ received a Solitaire stent (Medtronic, Dublin, Ireland), seven (14.9\%) obtained a Low-profile Visualized Intraluminal Support stent (LVIS; Microvention, Tustin, CA, USA), and five patients (10.6\%) received an Enterprise stent (Codman Neurovascular, Raynham, MA, USA).

Of the 47 patients, thromboembolic events occurred in four patients $(8.5 \%)$ during the follow-up period. However, there was no evidence that this correlated with the procedure, because these events occurred outside of the treated vessel in three out of four cases $(75 \%)$. Only one event $(2.1 \%)$ was correlated with the procedure. This patient was a 77-year-old woman, who underwent the procedure on an anterior communicating artery with an aneurysm $4.4 \mathrm{~mm}$ in size. Pre-PRU was 194, postPRU was 131, and the PRU variability was 63. One-year followup MRI revealed a dot-like infarction in the left frontal lobe with no symptoms (Fig. 1). Therefore, there was no significant factor correlated with a thromboembolic event statistically, due to low incidence.

In addition, there was no major bleeding complication according to the TIMI bleeding criteria. There were only 18 (38.3\%) minor bleeding complications. Sixteen patients (34\%) had purpura and two patients (4.3\%) had epistaxis and purpura. In univariate analysis correlated with hemorrhagic complication, pre-PRU and taking a statin were statistically significant $(p=0.002$ and $p=0.016$, respectively). In multivariate analysis, only prePRU was significantly correlated with hemorrhagic complication ( $p=0.033$, OR 0.983 , 95\% CI 0.968-0.999) (Table 3).

\section{DISCUSSION}

Following procedural neuro-interventions, the most critical complication is thromboembolic infarction. Many studies have been done to prevent such complications ${ }^{12,26)}$, but there are a few reports that demonstrate a correlation between the variability of antiplatelet response during antiplatelet drug medication and thromboembolic complications following a neurointervention $^{4,6)}$. Therefore, we investigated the variability of antiplatelet response during medication to determine any correlations with complications of endovascular treatment. In our study, PRU variability was greater in the Hypo-responsive group than in the Responsive group. This variability is in contrast to the initial clopidogrel response, as the Responsive group showed greater initial clopidogrel response. At one month after the clopidogrel regimen, overall clopidogrel response was slightly lower in the Hypo-responsive group than in the Responsive group. Whilst the initial clopidogrel response was significantly different between the two groups, it seems that due to a compensatory mechanism related to the higher PRU variability in the Hypo-responsive group, the final response rate was not significantly different (Fig. 2).

In the coronary intervention literature, some studies have reported on the etiology of variable responses to treatment with clopidogrel. Among affective factors correlated with clopidogrel response, the cytochrome P-450 enzyme was established to be the most important factor, correlated with genetic factors $^{2}$. In addition, some studies have reported that drugs which are metabolized by the cytochrome P-450 enzyme, such as statins, PPIs, CCBs, $\beta$-blockers and/or SSRIs, affect clopidogrel response, as well as patient clinical factors such as DM, renal failure, and/or $\mathrm{BMI}^{7,15,18,19,30)}$. In our study, pre-PRU and serum platelet count were important predictive factors, as in other studies ${ }^{10)}$. In the Hypo-responsive group, the reason for higher PRU variability could be a higher potential for increased response, as the initial clopidogrel response was low. In other words, a higher number of initially unresponsive platelets, which account for the low initial clopidogrel response, could suggest a higher probability of platelets becoming reactive as the ratio of initially unresponsive platelets is higher in the Hypo-response group. In addition, serum platelets count has shown differences in the variability of clopidogrel response. It is possible that if there were higher initial platelet counts, it would result in a higher clopidogrel response rate, due to increased drug receptors.

In regard to any correlation with complications, thromboembolic complication was not correlated with pre-PRU, PRU variability, or post-PRU. However, many studies have reported 

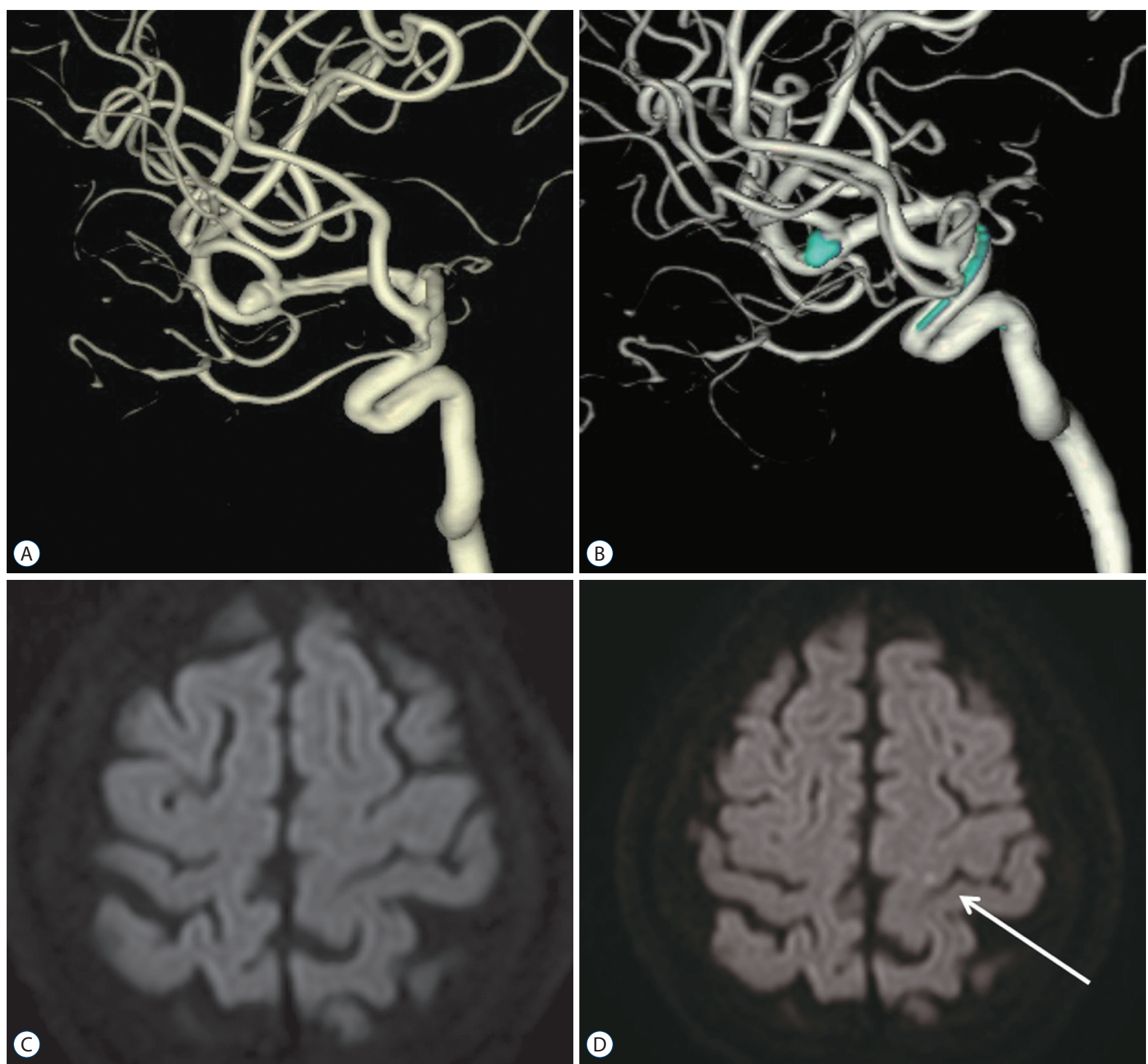

Fig. 1. The patient was a 77-year-old woman who underwent a stent-assisted coil embolization procedure on an anterior communicating artery with an aneurysm $4.4 \mathrm{~mm}$ in size. One-year follow-up magnetic resonance imaging revealed a dot-like infarction in the left frontal lobe, but no symptoms. A : Anterior communicating artery aneurysm on angiography before the procedure. B : Anterior communicating artery aneurysm on angiography immediately after the procedure. C: Diffusion weighted imaging at one day after the procedure. D: Diffusion weighted imaging at one year post-operation (the arrow indicates a dot-like infarction).

that HTPR after one-week preparation is correlated with thromboembolic infarction. Kim et al. ${ }^{14)}$ reported that acute thromboembolic infarction after endovascular treatment is a procedure-related complication. However, because delayed thromboembolic complication affects antiplatelet response, antiplatelet drug adjustment could decrease or delay thromboembolic complication in patients treated with $\mathrm{SAC}^{13)}$. In the current study, it is thought that statistical significance was lost due to too small of a sample size, with only one thromboembolic infarction case.

In contrast, hemorrhagic complication was correlated with a few factors, demonstrated in 18 cases of hemorrhagic complications. Patients with high pre-PRU values had less frequent hemorrhagic complications. However, there was no correlation 
Table 3. Variables associated with hemorrhagic complication in patients who received stent-assisted coil embolization

\begin{tabular}{|c|c|c|c|}
\hline & Hemorrhagic complication $(n=18)$ & Univariate ( $p$-value*) & Multivariate ( $p$-value $\left.{ }^{\dagger}[\mathrm{OR}, 95 \% \mathrm{CI}]\right)$ \\
\hline \multicolumn{4}{|l|}{ Clinical } \\
\hline Age (years) & $52.72 \pm 13.03$ & 0.109 & \\
\hline Gender (female) & $14(77.8)$ & 0.178 & \\
\hline Diabetes & $1(5.6)$ & 0.384 & \\
\hline Hypertension & $5(27.8)$ & 0.242 & \\
\hline Smoking & $1(5.6)$ & 0.384 & \\
\hline Alcohol & 0 & - & \\
\hline History of stroke & $2(11.1)$ & 1.000 & \\
\hline Heart problem & 0 & 0.517 & \\
\hline $\mathrm{BMI}\left(\mathrm{kg} / \mathrm{m}^{2}\right)$ & $23.84 \pm 4.13$ & 0.114 & \\
\hline \multicolumn{4}{|l|}{ Laboratory } \\
\hline Pre-PRU & $172.67 \pm 43.53$ & 0.002 & $0.033(0.983,0.968-0.999)$ \\
\hline Post-PRU & $55.72 \pm 45.01$ & 0.212 & \\
\hline PRU variability & $116.94 \pm 67.18$ & 0.450 & \\
\hline Cholesterol (mg/dL) & $179.27 \pm 31.49$ & 0.133 & \\
\hline $\mathrm{TG}(\mathrm{mg} / \mathrm{dL})$ & $122.13 \pm 52.65$ & 0.685 & \\
\hline $\mathrm{HDL}(\mathrm{mg} / \mathrm{dL})$ & $49.67 \pm 20.80$ & 0.507 & \\
\hline $\mathrm{LDL}(\mathrm{mg} / \mathrm{dL})$ & $112.960 \pm 28.30$ & 0.081 & $0.178(1.020,0.991-1.049)$ \\
\hline $\mathrm{GFR}(\mathrm{mL} / \mathrm{min})$ & $96.78 \pm 15.95$ & 0.085 & $0.788(0.993,0.940-1.048)$ \\
\hline Platelets $\left(10^{3} / \mu \mathrm{L}\right)$ & $239.94 \pm 56.94$ & 0.335 & \\
\hline \multicolumn{4}{|l|}{ Medications } \\
\hline Statin & $3(16.7)$ & 0.016 & $0.054(0.152,0.022-1.032)$ \\
\hline Metformin & 0 & 0.283 & \\
\hline $\mathrm{PPI}$ & $2(11.1)$ & 0.549 & \\
\hline H2-blocker & $11(61.1)$ & 0.188 & \\
\hline SSRIs & $1(5.6)$ & 1.000 & \\
\hline$\beta$-blocker & $1(5.6)$ & 1.000 & \\
\hline $\mathrm{CCB}$ & $4(22.2)$ & 0.372 & \\
\hline ACEi or ARB & $4(22.2)$ & 0.739 & \\
\hline Diuretics & $2(11.1)$ & 0.631 & \\
\hline Nitrate & 0 & - & \\
\hline Warfarin & 0 & 0.517 & \\
\hline
\end{tabular}

Values are presented as mean \pm standard deviation or number (\%) unless otherwise indicated. ${ }^{*} p$-value was determined with the chi-square test or Fisher's exact test in categorical variables and Student's t-test or Mann-Whitney test in parametric variables. ${ }^{\dagger} p$-value was determined with logistic regression analysis. OR : odds ratio, $\mathrm{Cl}$ : confidence interval, BMI : body mass index, pre-PRU : P2Y12 receptor reaction unit at admission, post-PRU : P2Y12 receptor reaction unit at 1 month after the procedure, PRU : P2Y12 receptor reaction unit, PRU variability : pre-PRU-post-PRU, TG : triglyceride, $\mathrm{HDL}$ : high density lipoprotein, LDL : low density lipoprotein, GFR : glomerular filtration rate, PPI : proton pump inhibitor, H2-blocker : histamine-2 receptor antagonist, SSRI : selective serotonin reuptake inhibitor, CCB : calcium channel blocker, ACEi : angiotensin-converting enzyme inhibitor, ARB : angiotensin II receptor blocker

with PRU variability or post-PRU. It is thought that the difference between the two groups disappears because platelets that have not reacted are converted to react after sufficient medication. In addition, it can be predicted that although thrombo- embolic complication was not statistically significant in this study, this may be significant in a larger study. Therefore, determining clopidogrel response after early-phase treatment is important for preventing complications. If this were deter- 

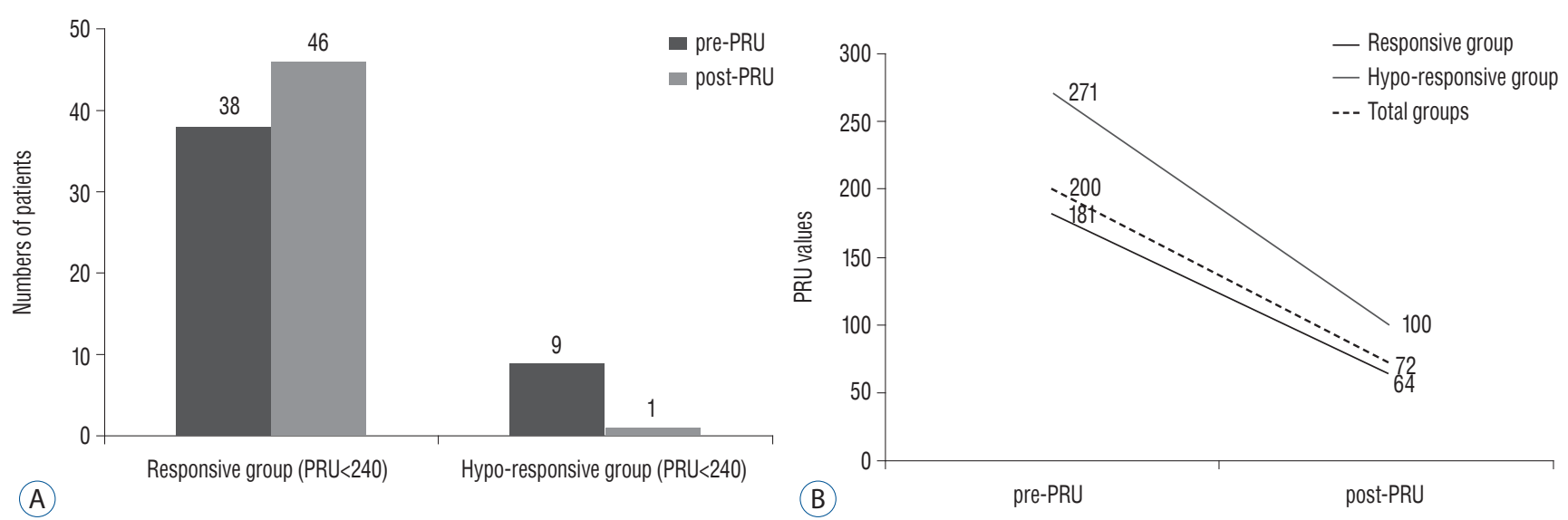

Fig. 2. Clopidogrel response variability in unruptured intracranial aneurysm patients treated with stent assisted coil embolization from initial response to one month after the medication. A : Responsive group vs. hypo-responsive group. B : The variation of PRU from initial response to one month after the medication. PRU : P2Y12 reaction unit.

mined, no additional response test would be necessary.

\section{Limitation}

This study has several limitations. First, this study has a small sample size and is retrospective in nature. Therefore, there might be a selection bias or compounding effects, such as minimal, transient symptoms that may have been missed in this analysis. To reduce this limitation, we performed MRIs regularly after one year and compared them with MRIs taken one day after the procedure. In addition, in order to exclude thromboembolic infarction caused by the procedure, like cracking the atherosclerotic plaque and dislodging thrombi due to use of wires or catheters, MRI was performed one day after the procedure ${ }^{14)}$. Second, among variables correlated with clopidogrel response, there was no significant factor correlated with thromboembolic complication, perhaps due to small sample size. However, since many studies have reported that the clopidogrel hypo-response is associated with thromboembolic infarction, our results would have been similar if the sample size of our study were larger ${ }^{8}$. In addition, because the results of hemorrhagic complication were similar to those of the previous studies, this assumption is further supported ${ }^{6}$. Third, of the factors associated with clopidogrel response reported in cardiology, only the pre-PRU and serum platelet counts were significant in the multivariate analysis. It is thought that this is also perhaps due to the small study size. Despite reduced statistical power, probably due to small sample size, pre-PRU and serum platelet count was prominently significant, indicating their statistical strength.
In order to obtain optimal guidelines, well planned and larger prospective studies are necessary in the future.

\section{CONCLUSION}

Variability of clopidogrel response during the pre-operative medication regimen was related to the serum platelet count and the initial clopidogrel response. Thromboembolic and hemorrhagic complications were not related to the variability of clopidogrel response or clopidogrel response after one month of medication, but hemorrhagic complications were associated with the initial clopidogrel response. Therefore, patients undergoing SAC with UIA are recommended to be tested for initial clopidogrel response; no further tests would be necessary.

\section{CONFLICTS OF INTEREST}

The authors have no financial conflicts of interest.

\section{INFORMED CONSENT}

This type of study does not require informed consent. 


\section{References}

1. Akpek S, Arat A, Morsi H, Klucznick RP, Strother CM, Mawad ME : Selfexpandable stent-assisted coiling of wide-necked intracranial aneurysms: a single-center experience. AJNR Am J Neuroradiol 26 : 1223-1231, 2005

2. Angiolillo DJ, Fernandez-Ortiz A, Bernardo E, Ramírez C, Cavallari U, Trabetti $E$, et al. : Contribution of gene sequence variations of the hepatic cytochrome P450 3A4 enzyme to variability in individual responsiveness to clopidogrel. Arterioscler Thromb Vasc Biol 26 : 1895-1900, 2006

3. Brisman JL, Song JK, Newell DW : Cerebral aneurysms. N Engl J Med 355 : 928-939, 2006

4. Delgado Almandoz JE, Crandall BM, Scholz JM, Fease JL, Anderson $R E$, Kadkhodayan $Y$, et al. : Last-recorded P2Y12 reaction units value is strongly associated with thromboembolic and hemorrhagic complications occurring up to 6 months after treatment in patients with cerebral aneurysms treated with the pipeline embolization device. AJNR Am J Neuroradiol 35 : 128-135, 2014

5. Delgado Almandoz JE, Crandall BM, Scholz JM, Fease JL, Anderson RE, Kadkhodayan $Y$, et al. : Pre-procedure P2Y12 reaction units value predicts perioperative thromboembolic and hemorrhagic complications in patients with cerebral aneurysms treated with the pipeline embolization device. J Neurointerv Surg 5 Suppl 3 : iii3- iii10, 2013

6. Delgado Almandoz JE, Kadkhodayan Y, Crandall BM, Scholz JM, Fease $J \mathrm{~L}$, Tubman DE : Variability in initial response to standard clopidogrel therapy, delayed conversion to clopidogrel hyper-response, and associated thromboembolic and hemorrhagic complications in patients undergoing endovascular treatment of unruptured cerebral aneurysms. J Neurointerv Surg 6 : 767-773, 2014

7. Drazin D, Choulakian A, Nuño M, Kornbluth P, Alexander MJ : Body weight: a risk factor for subtherapeutic antithrombotic therapy in neurovascular stenting. J Neurointerv Surg 3 : 177-181, 2011

8. Fifi JT, Brockington C, Narang J, Leesch W, Ewing SL, Bennet $\mathrm{H}$, et al. : Clopidogrel resistance is associated with thromboembolic complications in patients undergoing neurovascular stenting. AJNR Am J Neuroradiol $34:$ : 716-720, 2013

9. Geyik S, Yavuz K, Yurttutan N, Saatci I, Cekirge HS : Stent-assisted coiling in endovascular treatment of 500 consecutive cerebral aneurysms with long-term follow-up. AJNR Am J Neuroradiol 34 : 2157-2162, 2013

10. Giustino G, Kirtane AJ, Généreux $P$, Baber U, Witzenbichler B, Neumann FJ, et al. : Relation between platelet count and platelet reactivity to thrombotic and bleeding risk: from the assessment of dual antiplatelet therapy with drug-eluting stents study. Am J Cardiol 117 : 1703-1713, 2016

11. Hwang G, Huh W, Lee JS, Villavicencio JB, Villamor RB Jr, Ahn SY, et al. : Standard vs modified antiplatelet preparation for preventing thromboembolic events in patients with high on-treatment platelet reactivity undergoing coil embolization for an unruptured intracranial aneurysm: a randomized clinical trial. JAMA Neurol 72 : 764-772, 2015

12. Hwang G, Kim JG, Song KS, Lee YJ, Villavicencio JB, Suroto NS, et al. : Delayed ischemic stroke after stent-assisted coil placement in cerebral aneurysm: characteristics and optimal duration of preventative dual antiplatelet therapy. Radiology 273 : 194-201, 2014

13. Kim MS, Jo KI, Yeon JY, Kim JS, Kim KH, Jeon P, et al. : Safety and efficacy of antiplatelet response assay and drug adjustment in coil embolization: a propensity score analysis. Neuroradiology 58 : 1125-1134, 2016

14. Kim MS, Jo KI, Yeon JY, Kim JS, Kim KH, Jeon P, et al. : Association between postprocedural infarction and antiplatelet drug resistance after coiling for unruptured intracranial aneurysms. AJNR Am J Neuroradiol 37 : 1099-1105, 2016

15. Maruyama H, Fukuoka T, Deguchi I, Ohe Y, Kato Y, Horiuchi Y, et al. : Response to clopidogrel and its association with chronic kidney disease in noncardiogenic ischemic stroke patients. Intern Med 53 : 215-219, 2014

16. Mehran R, Rao SV, Bhatt DL, Gibson CM, Caixeta A, Eikelboom J, et al. : Standardized bleeding definitions for cardiovascular clinical trials: a consensus report from the Bleeding Academic Research Consortium. Circulation 123 : 2736-2747, 2011

17. Mocco J, Fargen KM, Albuquerque FC, Bendok BR, Boulos AS, Carpenter $J S$, et al. : Delayed thrombosis or stenosis following enterprise-assisted stent-coiling: is it safe? Midterm results of the interstate collaboration of enterprise stent coiling. Neurosurgery 69 : 908-913; discussion 913-914, 2011

18. Nakagawa I, Park HS, Yokoyama S, Wada T, Hironaka Y, Motoyama Y, et al. : Influence of diabetes mellitus and cigarette smoking on variability of the clopidogrel-induced antiplatelet effect and efficacy of active management of the target $\mathrm{P} 2 \mathrm{Y} 12$ reaction unit range in patients undergoing neurointerventional procedures. J Stroke Cerebrovasc Dis 25 : 163171, 2016

19. Ojeifo O, Wiviott SD, Antman EM, Murphy SA, Udell JA, Bates ER, et al. : Concomitant administration of clopidogrel with statins or calciumchannel blockers: insights from the TRITON-TIMI 38 (trial to assess improvement in therapeutic outcomes by optimizing platelet inhibition with prasugrel-thrombolysis in myocardial infarction 38). JACC Cardiovasc Interv 6 : 1275-1281, 2013

20. Oxley TJ, Dowling RJ, Mitchell PJ, Davis S, Yan B : Antiplatelet resistance and thromboembolic complications in neurointerventional procedures. Front Neurol $2: 83,2011$

21. Park KW, Park JJ, Kang J, Jeon KH, Kang SH, Han JK, et al. : Paraoxonase 1 gene polymorphism does not affect clopidogrel response variability but is associated with clinical outcome after PCl. PLoS One 8 : e52779, 2013

22. Pierot $L$, Biondi $A$ : Endovascular techniques for the management of wide-neck intracranial bifurcation aneurysms: a critical review of the literature. J Neuroradiol 43 : 167-175, 2016

23. Pierot $L$, Wakhloo AK : Endovascular treatment of intracranial aneurysms: current status. Stroke 44 : 2046-2054, 2013

24. Qureshi Z, Hobson AR : Clopidogrel "resistance": where are we now? Cardiovasc Ther $31: 3-11,2013$

25. Roy D, Milot G, Raymond J : Endovascular treatment of unruptured aneurysms. Stroke 32 : 1998-2004, 2001

26. Ryu CW, Park S, Shin HS, Koh JS : Complications in stent-assisted endovascular therapy of ruptured intracranial aneurysms and relevance to 
Clopidogrel Response Variability in Neuro-Intervention | Kim MS, et al.

antiplatelet administration: a systematic review. AJNR Am J Neuroradiol 36 : 1682-1688, 2015

27. Siasos G, Tousoulis $D$, Stefanadis $C$ : Multiple mechanisms affect the clopidogrel response. J Am Coll Cardiol 53 : 900-901; author reply 901, 2009

28. Tousoulis D, Siasos G, Zaromitidou M, Oikonomou E, Maniatis K, Kioufis $S$, et al. : The impact of CYP2C19 genotype on cardiovascular events and platelet reactivity in patients with coronary artery disease receiving clopidogrel. Int J Cardiol 168 : 1594-1596, 2013

29. Wanke I, Forsting $M$ : Stents for intracranial wide-necked aneurysms: more than mechanical protection. Neuroradiology 50 : 991-998, 2008

30. Weisz G, Smilowitz NR, Kirtane AJ, Rinaldi MJ, Parvataneni R, Xu K, et al. : Proton pump inhibitors, platelet reactivity, and cardiovascular outcomes after drug-eluting stents in clopidogrel-treated patients: the ADAPT-DES study. Circ Cardiovasc Interv 8 : e001952, 2015 